\author{
Cláudio Perani, SJ \\ Informações do artigo \\ Recebido em 10/05/2018 \\ Aceito em 30/05/2018 \\ doi> 10.25247/2447-861X.2018.n244.p219-230
}

Resumo
Elaborado em 2008, numa conjuntura política
similar à atual no que diz respeito à desconfiança e
ao pessimismo em relação aos partidos e às
instituições em geral, Cláudio Perani levanta neste
artigo, de maneira bastante lúcida e sintética, os
principais problemas e desafios da realidade
brasileira, sempre fundamentado numa concepção
que privilegia a importância do poder da base social
da sociedade e a organização popular.
Palavras-Chave: Sociedade Civil. Movimentos
Sociais. Organização Popular.

O tema Sociedade civil, movimentos sociais e ONGs no Brasil é extremamente interessante, atual e muito debatido hoje na conjuntura política brasileira. Penso que a razão principal seja, de um lado, a desconfiança em relação à política partidária. Está presente no meio popular um grande pessimismo ao considerar os políticos e suas instituições. Afirma-se facilmente que a política não muda nada, que os políticos são corruptos e visam somente seus interesses.

Do outro lado, os próprios cientistas sociais - alguns deles - questionam hoje o caminho da política partidária, afirmando que quem decide é a economia globalizada que controla os vários governos e impõe seu poder. Com isso, partidos, Congresso, Governo perdem sua importância e são valorizados outros caminhos políticos como os vários movimentos sociais e outras iniciativas da sociedade civil.

São opiniões e afirmações questionáveis, evidentemente, mas que têm seu valor e refletem uma situação concreta em contínua mudança. Simplificando, podemos dizer que, em princípio, será necessário não excluir nenhum caminho político, mas procurar mudar e fortalecer tudo que possa favorecer a organização popular e seu poder.

Nesta conjuntura torna-se fundamental a discussão da relação entre a Sociedade Civil, com suas diferentes instituições e movimentos, e o Estado, sem a priori ficar dogmaticamente apegado a ideologia que podem impedir aberturas necessárias. Trata-se de uma relação, às vezes, tranquila, outras vezes, muito tensa; relação em contínua mudança pela mudança do poder institucionalizado e pelas diferentes visões dos movimentos sociais.

Essas páginas querem dar algumas informações sobre essas realidades, sem pretender dar um quadro exaustivo. Seria um trabalho impossível, não somente pelo limite 
do artigo, mas sobretudo pela complexidade da situação e pelas diferentes opiniões existentes. Pretendo levantar alguns problemas ou desafios existentes, evidentemente, influenciado pela minha visão política que privilegia a importância do poder da base social da sociedade e a organização popular. Não é fácil falar de sociedade civil, de movimentos sociais e de ONGs por razão que se trata de conceitos e entidades muito diversificados.

Sociedade Civil é um conceito muito antigo, querendo significar o estado ou a sociedade política, o espaço do cidadão politicamente ativo. Mais tarde a sociedade civil se diferenciou do estado, adquirindo princípios e formas próprias.

Com a industrialização ficou um conceito ligado ao desenvolvimento capitalista, considerado como sinônimo de sociedade burguesa. Era a expressão da soma dos interesses particulares ou privados dos indivíduos enquanto portadores ou proprietários de bens econômicos. Em síntese, tinha um conteúdo eminentemente econômico.

Somente com Antônio Gramsci a sociedade civil é considerada pertencente à superestrutura política e cultural e não mais à estrutura econômica. Se num primeiro momento a sociedade civil indicava mais os instrumentos político-culturais com os quais a classe dominante exercia sua hegemonia (através da igreja, das escolas, dos sindicatos), mais tarde, pelas pressões dos trabalhadores e dos setores populares que abriram brechas nos limites políticos e sociais existentes, começou a significar as organizações independentes do estado, que se opunham às estruturas dominantes da sociedade.

Hoje a sociedade civil aparece como campo onde se expressam e se organizam interesses diferentes. Daí sua ambiguidade e complexidade. Trata-se de uma rede de aparelhos privados de hegemonia, isto é, de organismos sociais relativamente autônomos frente à sociedade política. No entendimento dos setores progressistas da sociedade, habitualmente, é um espaço onde as classes subalternas podem obter a hegemonia no interior do poder, uma arma contra as pretensões globalizantes de um estado totalizante. Aqui no Brasil, diria que no fim da década de 1980 tornou-se um conceito mais ligado a organizações de setores populares, indicando um caminho para uma nova sociedade.

Por Movimento Social entende-se, em sentido mais amplo, qualquer iniciativa popular para melhorar sua situação de vida e reivindicar seus direitos. É o povo que se mexe para poder sobreviver, inventando várias iniciativas, individuais ou mais coletivas, para encontrar um espaço próprio nesta sociedade. Em sentido mais restrito e habitual, são todos os movimentos e as organizações populares para reivindicar direitos fundamentais de uma 
vida digna. Podem ser iniciativas de caráter mais econômico, como, por exemplo, o vasto campo da economia solidária, ou de caráter social ou político.

Há uma grande variedade de movimentos sociais, o que significa, de um lado, a possibilidade de reconhecer a riqueza das iniciativas populares para reivindicar suas demandas e seus direitos; do outro, a necessidade de definir melhor cada movimento, com sua especificidade de objetivos e organização, tarefa não fácil diante da grande diversidade.

Os Movimentos Sociais são grupos que se movimentam na defesa de interesses comuns, apresentando algumas características próprias: nascem de uma necessidade sentida pelo grupo todo; produzem uma união entre os membros que dispensa uma grande organização; desfazem-se quando atingem o objetivo; caracterizam-se pela espontaneidade (no sentido de "fonte germinal", não em oposição à consciência e à organização); possuem uma consciência clara quanto ao objetivo visado, menos quanto às implicações políticas mais gerais; olham com suspeita toda vanguarda; favorecem: uma democracia de base; a busca de transformações que sejam fruto da vivência quotidiana; o questionamento da política; a crítica de uma direção centralizada; a abertura política de espaço para problemas da vida pessoal; a busca de uma maior integração entre vida privada e pública.

São diferentes das instituições (associações, sindicatos, partidos), organizações mais estáveis e imprescindíveis, mas com maior risco de burocratização. Nem se identificam com as Organizações Não-Governamentais - ONGs, que são, habitualmente, equipes de assessoria com bandeira própria, mas sem uma base mais ampla popular.

Querendo uma definição mais restrita, também no Brasil se recorre à definição de Alberto Melucci que afirma que se trata de uma ação coletiva, cuja orientação comporta solidariedade, manifesta um conflito e implica uma ruptura dos limites de compatibilidade do sistema ao qual se refere. Solidariedade é a capacidade dos atores de se reconhecerem e serem reconhecidos como parte da mesma unidade social; conflito exprime a relação de oposição entre dois ou mais atores que se confrontam para o controle dos recursos; ruptura dos limites significa romper as regras do jogo, propor objetivos não negociáveis, colocar em questão a legitimidade do poder.

A questão fundamental, segundo Melucci, é a existência ou não de um conflito sistêmico: significa que o movimento social está em posição antagônica com o atual sistema econômico-político, isto é, com o capitalismo em sua forma atual de neoliberalismo. Os 
conflitos, evidentemente, não existem somente nas questões de classe e de raça, mas entram também no campo das questões culturais.

Noutras palavras, a ação coletiva deve levar a romper os limites dos comportamentos admitidos, indo além das leis reconhecidas e forçando uma nova estrutura que o atual sistema não pode tolerar.

Segundo o autor, não podemos falar de movimento social quando as ações coletivas se situam no interior dos limites de variabilidade estrutural de certo sistema de relações sociais, sendo simplesmente fenômenos de manutenção da ordem estabelecida.

Para dar alguns nomes, podemos lembrar os movimentos mais estáveis com representatividade nacional: Movimentos dos Sem Terra, um dos mais conhecidos também internacionalmente; Movimento do Atingidos pelas Barragens; Movimento dos Sem Teto; Movimento Nacional dos Seringueiros; Movimento dos Ribeirinhos e Ribeirinhas; os vários Movimentos Negros; os muitos Movimentos Indígenas; Movimentos de Mulheres etc. Deveríamos acrescentar as mobilizações mais amplas com manifestações periódicas, como o Grito dos Excluídos, as Assembleias Populares, as Semanas Sociais, os diferentes Fóruns Sociais etc.

Esse limitado quadro fenomenológico permite de constatar, seja a diversidade e novidade de organização, seja a grande variedade de bandeiras. A estrutura dos movimentos sociais, em geral, é menos rígida, sem liderança autoritária, mais flexível para adaptar-se às novas exigências, sem normas e compromissos fixos, sem um plano estratégico bem traçado. Isso pode explicar a maior facilidade para mobilizações, mas também pode constituir a fraqueza dos movimentos.

A variedade das reivindicações dos movimentos representa a grande novidade no panorama das lutas para uma nova sociedade. Não se fala unicamente de trabalho, de leis trabalhistas e de desemprego. Aparecem vários direitos: da terra, da moradia, da água, do transporte, do lazer, da educação, da participação política; entram questões de gênero, de etnia, de sexualidade, da terceira idade, assim como questões de identidade, de raízes culturais, de consciência ambiental. Tudo isso amplia o leque das lutas políticas e favorece o crescimento de uma consciência mais autônoma e mais lúcida.

Não podemos deixar de mencionar as iniciativas de economia solidária, essas também bem diversificadas, tendo, porém uma boa porcentagem que pode ser considerada como economia não capitalista, mesmo que realizada numa sociedade capitalista. Trata-se de 
empreendimentos, habitualmente, familiares, tipo cooperativa que surgem, sobretudo na zona rural. Não visam o lucro, mas satisfazer as necessidades básicas de seus membros, e têm uma gestão autônoma e participativa, eliminando as relações dependentes de trabalho. Representam um sinal bem interessante, pois demonstram a possibilidade de realizar uma economia não capitalista antes de conquistar o poder do estado. É difícil poder dizer, no estágio atual de desenvolvimento, até que ponto essa economia poderá crescer e vingar e transformar-se numa alternativa ao atual modelo de desenvolvimento.

As Organizações Não-Governamentais - ONGs. Se no âmbito dos movimentos sociais encontramos uma grande variedade, essa existe muito mais no vasto campo das Organizações Governamentais. Num universo de cerca de 300.000 fundações sem fins lucrativos, no Brasil, as ONGs são mais de 7.000.

E entre elas há grande diversidade de objetivos. Podemos encontrar ONGs unicamente interessadas em procurar dinheiro para fins particulares, ligadas a políticos ou a pessoas interesseiras. Há um vasto setor de ONGs que recebem dinheiro do governo e que dificilmente poderiam ser chamadas de "não governamentais", e ONGs que prestam um serviço de assessoria muito importante e válido.

A preocupação com a corrupção que atingiu também o setor das ONGs foi tamanha que o Congresso sentiu a necessidade de instituir uma Comissão Parlamentar de InquéritoCPI para ter maior clareza sobre estas entidades pouco fiscalizadas. Atrás desta decisão há motivos políticos não bem declarados, mas certamente a CPI está servindo para revelar caminhos espúrios. Para sua averiguação, ela escolheu 250 ONGs que receberam por ano mais de $\mathrm{R} \$ 200.000$, o0 reais pelo governo federal, sem contar eventuais recursos estaduais e municipais. Trata-se de uma quantia que, por si só, pode levantar dúvidas sobre os verdadeiros objetivos destas entidades.

Um exemplo típico de dependência do governo é o Grupo de Trabalho Amazônico GTA, que reúne 602 organizações ambientais. Sem negar sua contribuição positiva em várias ocasiões, sabemos que recebe financiamento do governo e de bancos estrangeiros. Isso significa a necessidade de defender a política governamental, como no caso da Lei das concessões florestais, muito criticada por cientistas sociais e pela Comissão Pastoral da Terra da Amazônia e, ao contrário, defendida pelo GTA.

Mais interessante é conhecer os objetivos das ONGs preocupadas em buscar e defender alternativas de desenvolvimento humano e sustentável que considere a justiça 
social como compromisso fundamental de sua atuação. Para isso podemos recorrer à Associação Brasileira de Organizações Não-Governamentais - ABONG, que nasceu em 1991, reunindo as ONGs mais sérias e atuantes na perspectiva de uma sociedade nova.

A ABONG tem por objetivos: promover o intercâmbio entre entidades que buscam a ampliação da cidadania, a constituição e expansão de direitos, a justiça social e a consolidação de uma democracia participativa. Sua constituição é fruto de uma trajetória de um segmento pioneiro de organizações não governamentais que têm seu perfil político caracterizado por uma tradição de resistência ao autoritarismo, pela contribuição à consolidação de novos sujeitos políticos e movimentos sociais, pela promoção de direitos, pela construção da cidadania e pela defesa da ética política.

Devemos lembrar que muitos dos fundadores dessa ONGs mais politizadas foram pessoas militantes de partidos de esquerdas que tiveram uma dolorosa experiência durante a época da ditadura, foram torturados e exilados, e que - depois da volta ao Brasil - tentaram caminhos novos.

As ONGs associadas são mais de 250. Podemos somente citar uma das mais famosas e atuantes, o Instituto Brasileiro de Análises Sociais e Políticas - IBASE, que tomou a iniciativa da fundação da ABONG.

\section{A Política do Estado}

O Estado Brasileiro sempre reconheceu e apoiou organizações sem fins lucrativos de perfil mais assistencialista, voltadas à prestação de serviços públicos nas áreas de assistência social, saúde e educação. A partir do momento em que o Estado reconhece um segmento de organizações da sociedade civil como de utilidade ou interesse público, consequentemente cria uma relação privilegiada com essas organizações, que se concretiza em uma maior facilidade de acesso a recursos públicos de forma direta ou indireta.

O caso das ONGs é muito diferente. Não existe uma identidade comum entre hospitais e centro de educação privados, centros assistenciais, clubes recreativos e esportivos, creches, abrigos, de um lado, e do outro, as organizações não-governamentais com objetivos mais políticos de mudança que podem se opor à política do governo. 
A perspectiva do Estado foi sempre aquela de instrumentalizar as entidades sem fins lucrativos atribuindo a elas papeis paraestatais. O mesmo devia acontecer com as ONGs. $\mathrm{Na}$ década de 1990, com os novos atores nos processos sócio-políticos em curso e no clima da política de privatizações, o governo ampliou o conceito legal de público, tendo ocorrido um avanço no reconhecimento, por parte do Estado, de novas áreas de atuação consideradas de interesse público e estabelecendo políticas de financiamento para as OS (Organizações Sociais na saúde), as OSCIPs (Organizações Sociais de Interesse Público) e as ONGs. Contudo, a nova lei no que se refere a repasse de verbas apresenta falhas e lacunas. No mesmo tempo, o governo terceirizou vários setores da área social.

A ABONG, desde o seu surgimento, pleiteando o direito a recursos públicos, preocupa-se com a necessidade de uma melhor definição jurídica, que reflita os avanços e complexidades da maturação política das organizações da sociedade civil no processo democrático brasileiro. Não deixa de existir certo equívoco, pois uma ONG na hora em que recebe recursos do governo com dificuldade vai poder manter sua autonomia.

Com o início do governo Lula, em 2003, a relação entre o estado e os movimentos sociais mudou bastante. Do ponto de vista jurídico, a Política Nacional de Assistência Social - PNAS inova ao reconhecer que entidades defensoras de direito integram o campo da assistência social.

Mais interessante é constatar como evoluiu a relação prática dos movimentos sociais com o governo Lula. Num primeiro momento, houve certa desmobilização dos movimentos, sobretudo a nível nacional, sendo que a eleição de Lula significava para eles a conquista do poder e, certamente, uma mudança de política em favor dos setores populares. As mobilizações tradicionais não teriam mais sentido. Num segundo momento, Lula não foi mais unanimidade entre os movimentos sociais. Uma reduzida parcela tem duras críticas ao governo Lula por manter elementos de uma política econômica neoliberal. Outros setores, apesar das críticas, reconheceram a mudança no sentido de dar mais espaço aos movimentos sociais, mas no mesmo tempo perceberam a necessidade do papel próprio desses movimentos, mesmo com um governo mais favorável, e voltaram a se organizar. Somente o setor sindical apóia Lula de forma mais decidida por razão dos benefícios que recebe. 


\section{Alguns desafios atuais}

Relação Movimentos Sociais - Partidos

Talvez, seja uma das questões fundamentais na construção de uma nova democracia. Há posições extremistas que criam um dualismo entre os dois âmbitos da luta, os movimentos e os partidos. Anos atrás o único e fundamental caminho para uma mudança era o do partido revolucionário. Depois, ao constatar a insuficiência dos partidos e o surgimento dos movimentos populares, estes foram considerados como principal caminho, se não único. É claro que não se deve opor movimentos a partidos, excluindo um dos dois. Os movimentos precisam dos sindicatos e dos partidos; esses últimos necessitam dos movimentos. O partido continua como espaço importante para uma mudança, mas não como única forma de enfrentamento.

Os movimentos sociais conseguem mobilizar mais as pessoas a partir de bandeiras específicas e flexibilizando a organização.

Contudo, existe o perigo da fragmentação, pois as novas bandeiras podem ser defendidas sem relacioná-las com as "condições materiais" da luta, quer dizer, com a questão do trabalho, parcializando assim a visão da realidade. Há necessidade de algo que unifique e este é propriamente o papel do partido.

De outro lado, o partido desligado da relação constante com os movimentos sociais, corre o risco de burocratizar-se e de afastar-se das verdadeiras demandas populares. Os movimentos sociais são sempre necessários também quando o governo se diz ou é, de fato, de esquerda.

Sem dúvida, na medida em que desejarmos uma democracia não somente representativa, mas também sempre mais participativa, valorizando o poder popular, os movimentos sociais devem ser considerados e se apresentam como caminhos políticos novos e fundamentais.

Lideranças e Militância

Também os Movimentos Sociais, como toda e qualquer instituição, estão sujeitos a tensões internas que podem enfraquecer sua atuação. Uma dessas tensões depende da 
maneira com a qual aqueles que são chamados de "lideranças" ou "militantes" atuam e se situam no movimento. No Brasil temos exemplos claros de lideranças oportunistas e interesseiras, chegando com isso a esvaziar o movimento.

Essas duas palavras - líder e militante - vêm de contextos muito diretivos, o contexto da psicologia social comportamentista e o contexto militar, e revelam uma orientação bem autoritária. O líder é aquele que sabe e consegue cooptar os outros, motivando-os para cumprir a tarefa da organização; o militante é aquele que observa uma disciplina rígida e imposta para a vitória da causa. São termos que diminuem o sentido da autonomia e da subjetividade em benefício de uma bandeira que deve ser defendida.

Ora, habitualmente, uma das afirmações freqüentes dos movimentos sociais, hoje, é considerar todo membro como protagonista: trata-se de romper com a dependência e o autoritarismo, querendo que os "pobres" sejam sujeitos históricos da mudança e, portanto, de seus movimentos e iniciativas. Trata-se de gerar "autores", quer dizer, pessoas que no movimento desenvolvem sua criatividade, se realizam e participam continuamente do poder de decisão, criando um novo tipo de relações sociais. Ainda que às custas de uma aparente lentidão inicial. O desafio, no caso, é o de como realizar isso na prática, o que nem sempre é fácil.

A questão da articulação

Devemos considerar o problema da articulação dos movimentos, quer dizer, da capacidade do movimento local crescer e se relacionar num âmbito maior, no nível estadual e nacional, problema fundamental e delicado, sobretudo considerando o pluralismo das organizações e das bandeiras de luta.

É o grande desafio e de difícil encaminhamento. Só para citar um caso. O Movimento dos Sem Terra, as Organizações Indígenas, o Movimento dos Ribeirinhos e dos Quilombolas estão lutando pela mesma reivindicação, o direito à terra. Dificilmente se ouve falar de encontros entre esses movimentos para somar forças.

É evidente que uma excessiva fragmentação pode levar a um enfraquecimento do poder popular e nenhuma dúvida que deva ser colocado o problema da unidade. Este é uma questão complicada: facilmente passa a ser simples redução, ou porque é realizada na mesa, por algumas lideranças, sem a participação de uma base mais ampla; ou porque se eliminam 
ou acrescentam bandeiras sem concordância popular. Deve-se encontrar mecanismos concretos e eficazes de unidade. Temos na Amazônia alguns exemplos. A Aliança dos Povos da Floresta procura unir as forças dos seringueiros e dos indígenas. Multiplicam-se, no Brasil inteiro, os fóruns e as redes, mecanismos novos que conseguem o diálogo entre diferentes experiências.

Contudo, volta aqui o problema da relação necessária entre partidos e movimentos sociais. Os primeiros, em tese, são aqueles que procuram realizar a unidade entre os vários caminhos possíveis, tendo, porém, dificuldades de se relacionar com as bases.

Os segundos conseguem captar melhor e defender os interesses populares. Uma relação dialética entre os dois caminhos da democracia parece ser indispensável para a construção de uma nova sociedade.

As parcerias

Há algo de mais difícil e de mais sutil para ser discernido: o problema das parcerias. Nos últimos anos, aproveitando da "abertura" do governo nos vários níveis, municipal, estadual e federal, alguns movimentos, entidades populares, pastorais, entraram em parceria com o próprio governo, quer dizer, aceitaram desenvolver trabalhos em comum. Com a fundação dos Conselhos Paritários, representantes populares ocuparam espaços nesses conselhos. Às vezes, era aceito o apoio de uma ONG disposta a oferecer sua ajuda para potencializar o movimento. Tudo isso, pensando de adquirir mais poder pelo fato de ocupar um espaço de governo ou de ter mais recursos materiais. Consequências: muitos movimentos ficaram somente neste nível e deixaram o nível mobilizador e reivindicatório; a atuação mais operacional e propositiva reduziu-se ao nível dos conselhos.

Em tese poderia ser um caminho bem acertado, na prática muitas vezes contribuiu para enfraquecer a oposição popular.

Colocar o pé num espaço de governo pode ser válido na medida em que se mantém o outro fortemente fincado na mobilização popular, caso contrário a força do movimento não aumenta, mas diminui.

Vários são os exemplos que poderiam ser apontados. Uma recente pesquisa vem confirmar essas afirmações. O MAPAS (Movimento Ativo da Participação da Sociedade), encarregado da pesquisa, focalizou os instrumentos criados ou reformulados pelo atual 
governo: o Conselho de Desenvolvimento Econômico e Social, a Conferência para o Meio Ambiente, o Conselho das Cidades e o Conselho Nacional de Segurança Alimentar. Eis algumas conclusões: "Os movimentos sociais estão acurralados. Integrados a instâncias criadas pelo governo Lula, viram suas exigências caírem no vazio. Precisam voltar às ruas para exigir o cumprimento delas".

É importante reconhecer que os movimentos sociais, com sua especificidade e objetivos, sempre serão necessários, qualquer que seja o sistema político. Por isso, devem manter sua autonomia.

Outro conceito de desenvolvimento?

Temos que constatar que o atual tipo de desenvolvimento fracassou. A riqueza aumenta sempre mais e, com ela, também a pobreza de muitos. O conceito de desenvolvimento foi importado do ocidente e sempre orientou a política brasileira, também a atual que se considera de esquerda. É um desenvolvimento que visa a produção e o lucro, criando em todo lugar sociedades de trabalhadores e consumidores. Resultado: as desordens sociais e a destruição ambiental aumentaram.

É um sistema que tem sua lógica e suas regras, incorporadas, muitas vezes, também pelas lideranças dos movimentos sociais e das ONGs, seja brasileiras seja de origem estrangeiras. Essas últimas, habitualmente, fazem um trabalho de conscientização e de denúncia importante, apóiam as lutas de libertação dos setores oprimidos, procuram favorecer a autonomia local e o desenvolvimento endógeno. Mas, apesar da boa vontade, os resultados são contraditórios pela visão de desenvolvimento, consciente ou inconscientemente incorporada.

Só para citar um exemplo. No Amazonas, faz anos, os ribeirinhos, diante da invasão da pesca predatória em seus lagos, desenvolveram uma luta para defender seu peixe, com a ajuda da Comissão Pastoral da Terra. Escolheram um lago para a reprodução dos peixes, onde ninguém podia pescar; outro para a manutenção própria, onde só a comunidade podia pescar; e ou outros livres.

Organizaram-se para a defesa desse sistema e conseguiram, nalguns municípios, introduzir uma legislação das águas inovadora no Brasil inteiro. Chegou uma ONG estrangeira, conheceu o trabalho, gostou e quis ajudá-lo para fortalecê-lo mais. Assalariou 
algumas pessoas, sugeriu a formação de várias associações com seu estatuto tradicional etc. Consequências: depois de certo tempo os ribeirinhos não conseguiram mais sustentar a nova estrutura e a luta pela defesa dos lagos enfraqueceu.

Podemos constatar quanto seja delicada e complexa a ajuda que as ONGs ou outras entidades pretendem dar aos movimentos populares. É o problema da cooperação internacional que é geralmente orientada por valores da cultura ocidentalmodernatecnológica e que tem uma visão bastante negativa das outras culturas. Mas é problema também dos movimentos sociais e das ONGs brasileiras que incorporam inconscientemente essa visão de desenvolvimento.

Para concluir, se de um lado constatamos um bom crescimento dos setores populares que, através de seus movimentos e com ajuda de ONGs comprometidas, conseguiram e estão conseguindo muitas vitórias, do outro lado percebemos que o caminho é muito comprido e que deve ser pensado e realizado outro tipo de desenvolvimento que saiba respeitar e integrar melhor as diferentes culturas. Tarefa imensa e complexa.

\section{Referências}

MELUCCl, Alberto. A intervenção do presente: Os Movimentos Sociais nas Sociedades Contemporâneas, Petrópolis, Vozes, 2001.

\section{Dados do autor}

Cláudio Perani

Homenageado desta Edição Especial. 